Journal of Social and Development Sciences

Vol. 3, No. 5, pp. 172-179, May 2012 (ISSN 2221-1152)

\title{
Nakhon Phanom, The Third Mekong Friendship Bridge and the ASEAN Economic Community
}

\author{
Pornsakol Na Srito, John Walsh* \\ Shinawatra University, Bangkok, Thailand \\ *jcwalsh@aiu.ac.th
}

\begin{abstract}
This paper reports on research conducted in Nakhon Phanom Province in Northeastern Thailand among business-owners and other individuals about prospective and actual changes in economic and social conditions resulting from the opening of the Third Mekong Friendship Bridge and the ASEAN Economic Community, due to be launched in 2015. Qualitative research conducted with 35 key informants revealed that there had been few changes cause so far and little intention to change any more than necessary. Most respondents were waiting for the state to take a lead in information provision and in facilitating the ability to make changes. It is found that the Bridge has had some impact upon land prices and the labor market but that these changes remain limited because of the comparatively low level of usage of the Bridge.
\end{abstract}

Keywords: Infrastructure, labor migration, Mekong region,

\section{Introduction}

An important part of the Asian Development Bank's (ADB) developmental project for the Greater Mekong Sub-Region (GMS) has been to create transportation infrastructure to increase the possibilities of trade, migration and investment. Infrastructure is an enabling technology that permits both positive and negative aspects of movement, whether that is movement of people, goods or capital. It is the role of states to ensure that appropriate governance of areas newly connected takes place and that suitable protections are in place. Opportunities that have been opened by transportation infrastructure development in the GMS can be dominated by big capital driving out small capital (Gomez et al., 2011) or else take place in a form of cowboy capitalism in which the strongest takes all (Walsh, 2011). Alternatively, economic opportunities can drain away as the result of poor administrative, bureaucratic and technical support (Swe and Chambers, 2011). The developments have differential impacts on people based on economic capacity, location and gender. In some cases, the impacts magnify already existing impacts, while in other cases they destroy existing arrangements and allow new ones to be formed. In this second case, infrastructure helps the spread of capitalism through the process of Schumpeterian creative destruction. The ADB's GMS program has included a focus on the use of deliberately engineered uneven development. Landscapes develop in uneven manners as a result, initially of resource-locations and, subsequently, by the recreation of the terrain as means of producing goods and services for international markets (Smith, 2010; Harvey, 2011). In this case, economic corridors are being created which follow transportation infrastructure and which link previously remote locations as parts of new areas in which pressure is placed on administrative and bureaucratic structures to lessen their impact and facilitate trade, investment and migration. This includes the East-West Economic Corridor (EWEC), which is part of the overall Asian Highway Network and which is intended to link Vietnam's Da Nang in the east with Myanmar in the west and, ultimately, beyond that country. This concept was introduced in Thailand on January $11^{\text {th }}, 2005$, in a project that evolved into the Ayeyawaddy-Chao Phraya-Mekong-Economic Cooperation Strategy (ACMECS) and which aimed at promoting communications and links that would help, in part, to reduce poverty in the territories involved (ADB, 2010). The ADB is the lead agent in this project, supported by the Japan Bank for International Cooperation (JBIC), which has provided some $80 \%$ of the total of US\$900 million estimated to have been spent on the project thus far. Under the Vientiane Plan of Action (2008-13), the EWEC was identified as being an important component part of the overall strategy and was costed at US $\$ 23.1$ million (ibid.). In particular, the EWEC includes the opening of bridges across the River Mekong which, despite being in the top dozen longest and most significant rivers in the world, was not bridged before the first Friendship Bridge opened between Vientiane (Laos) and Nong Khai (Thailand) in 1994; the second bridge, opened in 2007, links Savannakhet (Laos) with Mukdahan (Thailand) and the third, opened in 2011, links Thakhek (Laos) with Nakhon Phanom (Thailand). 
Previously, the Chiang Khong (Thailand) to Houayxay (Laos) Bridge was referred to as the Third Friendship Bridge but has subsequently been redesignated as the Fourth. It is anticipated that the EWEC will bring positive economic benefits taken together and, indeed, results from elsewhere would support this optimism. However, large-scale or aggregate improvements tend to overlook the impact at the local level and the fact that, since people are differentially affected, there will certainly be losers as well as winners. It is important to conduct additional research that identifies the impacts at the community level and that helps to provide evidence that will mitigate the problems suffered disproportionately by some sections of the community (Rigg and Wittayapak, 2009). The current research project aims to make a contribution to this effort by analyzing changes made in Nakhon Phanom province as a result of its proximity to the EWEC. The ASEAN Economic Community (AEC) is due to begin in 2015 and it will signal a new phase in the creation of an open market within the ten Southeast Asian region. Under the AEC, skilled labor in various categories will be permitted free movement, as long as reciprocal standards can be achieved and agreed (Yukubousky, 2012). The number of categories of skilled labor that will be affected by this change is yet to be made clear and it is likely that more will be added as the results of cross-border, inter-industrial negotiations continue to bear fruit. Evidence from comparable agreements elsewhere (Vandamme, 2000) suggests that there will be more movement and, so, Nakhon Phanom will be affected both by such workers moving into and out of the province and, also, using the Bridge as a means of transit for local and more extensive transit. Nakhon Phanom is experiencing some of the same qualities that other areas in which labor mobility has been introduced have demonstrated: that is, lack of skilled workers, unemployment and under-employment locally for unskilled workers and an aging population (Zimmermann, 2005). In the case of Nakhon Phanom, in common with other of the poorer provinces of Thailand, the aging population has derived from the outward migration of many younger people elsewhere in the country. One of the principal objectives of this research is, therefore, to try to gauge the opinions of local people and organizations concerning the effects of the Bridge in the immediate present and the prospects of the AEC over the next few years. This has implications far beyond the geographical territory concerned. Around the world, numerous societies and regions are being placed under conditions of late capitalism as they are bound to international markets and distant places of production and consumption and millions of people will be involved. The ways in which communities will be affected by coming into contact with the creative destruction that is brought about by capitalism will be influential in shaping the ways in which countries will interact with each other in the future and the extent to which local and national actors will retain any power in their dealings with the rest of the world.

Nakhon Phanom: Nakhon Phanom is a province in the Northeast of Thailand, which, like much of that region, is lacking in manufacturing, industry and infrastructure. The reliance on agricultural production exposes the provincial economy to the volatility of the international environment and provides comparatively few opportunities for local people who do not wish to migrate to find other types of work. Its population is listed as 751,543 , of whom 446,974 are members of the labor market $(56.2 \%$ male and $43.8 \%$ female). The unemployment rate is $2.35 \%$. The Gross Provincial Product (GPP) increased by $10-15 \%$ from $2003-7$ (excepting 2005) with the principal component of growth being the non-agricultural sector, which contributes approximately $65-72 \%$ of GPP. Nevertheless, agriculture remains the largest single sector (26$34 \%$ of GPP), followed by wholesale and retail trades (17-20\% of GPP), education (12-15\% of GPP) and the public sector (7-8\%). Agriculture is dominated by paddy rice farming, which occupies 1,328,253 rai of land (221,160 hectares). Rubber tree planting has been increasing rapidly, having increased by $39.0 \%$ from 2008 $(133,056$ rai or 21,289 hectares) to 2009 (185,580 rai or 29,693 hectares). This was in part resulting from a government scheme to grow rubber wood in areas where deforestation had previously taken place, in preference to planting eucalyptus trees, which had proved to have negative ecological impacts. In addition, rubber prices have risen from $53.6 \mathrm{baht} / \mathrm{kg}$ in 2009 to $98.3 \mathrm{baht} / \mathrm{kg}$ in 2010 and $156.9 \mathrm{baht} / \mathrm{kg}$ in 2011 (DOAE, 2011). The increases in rubber prices reflects the global increases in commodity prices at the end of the first decade of the twenty-first century, which has been influential in driving higher overall inflation rates. Nakhon Phanom consists of a total land area of 3,445,418 rai (551,267 hectares), of which $43.0 \%$ is used for agriculture, $24.0 \%$ is covered by forest and the remaining $33.0 \%$ is used for non-agricultural purposes (OAE, Land utilization). Land prices have risen significantly in response to the building and opening of the bridge, although only in specific areas. For example, from 2003-6 to 2007-11, land prices in the downtown metropolitan area increased by 5-50\%, while the rural zone on the outskirts of the urban area but adjacent to National Road No.22 (Sakhon Nakhon-Nakhon Phanom) increased by some $25-60 \%$ over the same period. Meanwhile, the zone around the base of the Bridge, where construction has been taking place and adjacent to 
Provincial Road No.212 (Nakhon Phanom-Nong Khai) experienced land price increases of 20-67\%. Other areas also experienced land price increases linked to their proximity to the Bridge and potential economic development resulting from it. Nakhon Phanom has become better linked with both Bangkok and neighboring countries in recent years. Two budget air carriers, Nok Air and Air Asia, have begun to service the local airport from Bangkok and the Bridge itself links with Highways in Laos that connect with Vietnam to the east, Cambodia to the south and the Chinese border to the north. There is currently discussion within the Ministry of Transport and related agencies concerning the building of a rail link, possibly a high-speed rail link, with the regional capital of Khon Kaen, which will assist inwards and outwards distribution of goods in the Northeastern Isan region (Theparat, 2012).

\section{Literature Review}

The theory of comparative advantage argues that differential distributions of resources lead to an initial pattern of economic activities and societal settlements that see close geographical correlation between the place resources are found and where they are extracted or cultivated and processed (Ricardo, 2004). When resources are physically located in a particular area (e.g. coal, oil, minerals), then there is little option but to centre extraction activities there and normally a settlement will be established in that area to support the labor force and management requirements. However, as technology improves, the nature of comparative advantage changes as the need for labor in resource extraction declines, which new forms of comparative advantage may be nurtured and created in other, perhaps more convenient locations (e.g. Nahapiet and Ghoshal, 1998). First nature, when the landscape was untouched by human hand, has long given way to second nature, in which human endeavor has been influential in converting the landscape to more efficient economical use by such means as irrigation, constructing roads and railways and adapting crops and animals to the conditions available (Smith, 2010). Much of the Mekong Region, in common with most parts of the developed or developing world, are now unrecognizable from the state of first nature, particularly because of the spread of paddy farming, deforestation and urbanization (Jacobs, 1995). Despite some unfortunate negative externalities arising from these changes (e.g. environmental degradation, enhanced risk of flooding and landslides), it is apparent that the belief exists among planning officials and ADB officers alike that it is possible to manipulate the configuration of comparative advantage in a particular location in such a way as to promote economic development in the aggregate. To take further advantage of locational effects, agencies might organize an industrial estate or some other type of special economic zone (SEZ). Such a zone offers different laws and regulations with a geographical territory bounded in space and time and with a view to encouraging investment within the zone. The benefits of residents in an SEZ are usually described as Marshallian: that is, they can form part of clusters of industrial firms in a proximity that provides information spillover or imitation, division of labor among enterprises and the development of skilled labor markets (Marshall, 1920). Clusters are 'concentration of enterprises producing similar or closely related products in a small area' (Sonobe and Otsuka, 2006) and develop in four distinct stages: (1) initiation, (2) quantity expansion, (3) quality improvement, (4) 'eruption' (Otsuko and Sonobe, 2009).

SEZs have a lengthy history in Thailand and have contributed significantly to economic growth by providing spaces in which low labor cost manufacturing can take place with a view to subsequent exporting. Additional SEZs are being planned with respect to the Chiang Khong-Houayxay Friendship Bridge, mostly using Chinese capital (Swe and Chambers, 2011: 76-9) and aiming at taking advantage of locational and governance factors. There are no industrial estates located in Nakhon Phanom at present although incentives are available for the establishment of one. It is also known that such changes can have unintended consequences which, in line with the creative destruction of capitalism, provides both winners and losers. Trankell (1999), for example, describes the building of roads in Laos and their impact on the lives of villagers by whose homes the roads pass. She has a particular focus on the differential impact on gender and finds that roads generally help corporations in expanding their operations to new areas, while those able to drive vehicles (mostly men, for cultural reasons) have enhanced work and income-generation opportunities. However, since the roads rarely connected with the local facilities, which are part of women's daily lives and work, then they offered fewer improvements to them. In the Mekong Region in particular, it has been observed that too little is known about the actual effects of road building and that the process is too easily accepted as unproblematic results of development that effectively combat the 'bad' of remoteness (Rigg and Wittayapak, 2009). It is also true that the development of infrastructure appeals to funding bodies and government agencies because it provides 
quantifiable progress for money spent and helps, therefore, to justify the existence of projects, in the ADB and elsewhere. Previous attempts at attempting to promote state-led uneven development by designating special economic zones in cross-border regions have been aimed at providing complementarily of resources for synergistic growth. This has been successful to some extent in the Sijori project that links Singapore, Johor in Malaysia and Riau in Indonesia (Yip, 2000).

It was, however, less successful in the Tumen River Project, owing to lack of technical capacity and the political problems dividing collaborates including the Soviet Union (as it then was), China and North Korea (Kim and $\mathrm{Wu}, 1998$ ). Experience shows, therefore, that non-rational economic factors can be influential in determining whether or not a specific incident of planned uneven development is successful in its own terms or not. The extent to which the EWEC has had an effect on the physical and social environment of Nakhon Phanom, which is a province in the northeast of Thailand bordering the River Mekong, will be investigated in this paper. Nakhon Phanom is not directly proximate to the bridge but the road and the corridor do cross its territory. As a border region, Nakhon Phanom has for some years experienced a substantial presence of Lao migrant workers, owing to the significant difference in wages on either side of the river and the relative ease of crossing it. Lao workers, in common with other migrant workers in Thailand, are officially restricted in terms of permitted location and permitted occupation (Sciortino and Punpuing, 2009). Nakhon Phanom also experiences labor migration of its own young people, who are drawn to better paid jobs in Bangkok or the industrial estates and, hence, less willing to continue with the agricultural work which their families may have continued with for generations (e.g. Rigg et al., 2008). Nakhon Phanom continues to operate a crossMekong ferry service, which remains popular with local people and hauliers, notwithstanding the bureaucracy and costs involved. There does not appear to be the same level of international arbitrage found among entrepreneurs on the Lao side of the river as has been found at, for example, Savannakhet (Southiseng and Walsh, 2011).

\section{Methodology}

This research study was conducted by means of initial secondary research of existing documents and data and then qualitative fieldwork involving in-depth interviews with key informants and ethnographic observation of activities and lifestyle changes in the area of study. A semi-structured interview was constructed with reference to the secondary data review and the issues identified as the research questions. Each interview was conducted not as a means of answering a rigid series of questions in the same order with a view to statistical testing but as separate, independent conversations in which respondents were encouraged to explore issues of importance to them and of relevance to the research study. Extensive note taking accompanied the interviewing process and notes were subsequently transcribed for analysis. The language used was predominantly Thai, with some use of local dialects where appropriate. Although there are some differences between the central Thai dialect, the Isan dialect of Northeast Thailand and the Lao language, the three tongues are mutually comprehensible. In addition to one-on-one in-depth interviewing, focus groups and brainstorming, meetings were also convened for the further exploration of issues emerging from the literature review and the interviews and to identify possible problems in implementation of policies and recommendations. The data collection process was conducted in different periods of 2011. Once all transcripts were available for analysis, key issues were identified and summarized and these are presented in the course of the next section. Content analysis techniques were employed to interrogate the collected data and structure the insights and conclusions drawn from that data. Thirty-five key informants were identified and interviewed, twenty-six of whom were business-owners and others government officials and local farmers. All lived within $10 \mathrm{~km}$ of the Bridge. They had a range of different occupations, levels of education and ages. Respondents were selected based on maximum variability within a combination of convenience and snowball sampling methods. As a qualitative study that is based on in-depth face-to-face interviews, as explained above, the research may only be generalized to other situations and circumstances within some constraints. Qualitative research sometimes suffers from the fault that it describes a single situation very accurately but in a way, that inhibits extension of findings to other parts of the world. There is also the danger that a methodology relying on a combination of convenience and snowballing methods can suffer from the problem of an overly homogeneous sample. These issues have been tackled through the selection of respondents with a view to maximum variability given the constraints in place and, secondly, by attempting 
to broaden the context by placing the information and findings within an international context and with reference to regional issues.

\section{Results}

Preparations for the AEC: In common with reports from other parts of Thailand, respondents in Nakhon Phanom seem to have made very few or no preparations for the forthcoming AEC. A total of 19 businessowners reported that they had made no preparations at all; five of them because of lack of information and a further three because they were awaiting information or documents from some branch of government. Five company-owners reported that they were preparing the expand the business in preparation for 2015 and two more that plans were in hand to increase the training of staff members. One of the principal reasons for this lack of preparation is the provincial nature of many companies in the province. Several hotel owners, for example, observed that there was little need for change because most customers are Thai people attending local events or business activities and it was not considered that this would change very much. There was, it was agreed, little potential for developing Nakhon Phanom as a tourist destination for Lao or Vietnamese tourists and that increased use of the Bridge would be conducted on a transactional basis: that is, people use the Bridge as part of a journey elsewhere rather than to reach a destination in the vicinity. Further, manufacturing and assembly companies in the province tended to be parts of the supply chain for larger factories and, as a result, have only limited capacity to affect the business conditions in which they work and, instead, respond to conditions imposed by more powerful partners at other parts of the value chain. In general, therefore, it is apparent that business in Nakhon Phanom as represented by this research is reactive in nature rather than proactive and companies are likely to suffer from significant shocks in the external environment. There is, nevertheless, still time to improve this situation before the inauguration of the AEC in 2015. It would appear to be necessary for government to lead this effort, since so many respondents rely on government agencies to provide information and assistance in owners of this sort.

Perceptions of the Bridge: Respondents reported that they had been informed of the forthcoming building of the bridge by political representatives, who had brought the news four or five years previously. This is not surprising as it has since the beginning of the development period in Thailand been common for local politicians to claim responsibility for bringing development projects to benefit local electors (Ockey, 2005: 16). Respondents felt that it was possible that opening the bridge would benefit local residents either because it would lead to higher tax revenues at the provincial level or that landowners would enjoy higher land prices (which, as mentioned above, do seem to have taken place). There was also a feeling that organizing the bridge building was done in order to benefit those landowners who could take advantage of the increased prices. However, improved infrastructure should also benefit the people of the province as a whole, as would the prospect of new employment and general 'community development.' Respondents felt that these positive externalities would arise once traffic across the bridge began to flow but did not articulate exactly how this would happen or what role they themselves might be playing. However, there was fear of the negative consequences of the bridge. These ranged from fear of large numbers of illegal aliens arriving, as well as possible increases in illegal drugs smuggling and the problems that future residents will suffer because of elevated land prices they would not be able to afford. Further, respondents were concerned about the apparent lack of long-term and large-scale thinking and planning and the implications this will have for future change. "Globalization" was mentioned as a potential cause of future change and this is a term that now has accumulated negative connotations in Thai society. Another respondent discussed the need for people to be prepared for the changes that might occur: "Stakeholders in each category should prepare themselves for the forthcoming situation after the bridge opens ... those who are traders should create a vision for cross-border trade and consider the differences in comparative advantages that will result, since we will be much closer to the Vietnamese coast ... we should learn from the building of the first bridge at Nong Khai and the second at Mukdahan."

It was felt that developing suitable vision was hampered by the lack of integrated planning activities in the local government level and the fact that 'paper plans' are not the same as genuine plans for implementing new policies. Further, it was observed that only public sector agencies had been consulted in planning the bridge and there had been insufficient opportunity for providing input by the private sector. As a result of this, respondents felt that it would be large investors who would benefit from the bridge and that there would 
be few if any improvements for SMEs and the grass roots people and communities. "There will be no benefits to the community from the bridge. Benefits will only come for investors." It was felt that this was part of a pattern of development projects that had previously promised benefits for local communities, which had subsequently failed to materialize. There was also a structural reason for this effect, which was that local people had already been tempted by the rising prices into selling their land. While they therefore had the cash, they were not able to benefit from the increased economic activities over the long-term. As has been observed in other research studies, farming land is being sold to investors and fewer young people are interested in farming as a long-term occupation. This is resulting in social as well as economic change in affected areas and the burgeoning fear of the ebbing away of the traditional patterns of life. Meanwhile, the fabric of society will be damaged as large investors will increasingly be able to take advantage of opportunities to make profits, while local people must suffer from the air and noise pollution produced by the large numbers of trucks which can be expected to thunder along the roads, creating danger of accidents. New interest groups will emerge from the changed conditions and replace the previous power structures. In some cases, it might be possible for village people who have sold their land and who are, perhaps only temporarily, cash-rich as a result might be able to leverage that cash for an improved social position and investment for long-term gains. However, overall, pessimism tended to outweigh optimism, perhaps because of a lack of imagination concerning how the changed situation might be used to personal advantage and awareness of how existing arrangements will be less profitable in the future. For example, the land sales had contributed to localized increases in the cost of living that were manifested in rising labor prices. Some respondents estimated that labor costs had increased from 150 baht per day a few years previously to some 250 baht per day at the time of interviewing (which was prior to the 2011 election and the manifesto promise of the victorious Pheu Thai party to increase daily minimum wage rates to 300 baht per day). It was felt that this would contribute to the existing shortage of labor in the agricultural sector.

Nakhon Phanom and the Regional Development of Thailand: The Thai government has in recent decades devoted some attention to the issue of decentralization of the economy and this process intensified under the 2001-6 Thai Rak Thai administration and is expected to re-emerge under the current Pheu Thai administration. Thailand has long faced the problem that its capital city, Bangkok, is a primate city that contains within its confines all the principal political, cultural, religious and commercial institutions and that there is no other urban centre which can even be measured against it. When the period of rapid industrialization began in the 1960s, it was logical to place industrial estates near Bangkok because that was where the suppliers and customers of products were overwhelmingly found. However, this concentration of activities has contributed to negative environmental impacts, rising income inequalities, public health issues, internal migration and its social effects and notorious traffic congestion. For a variety of reasons, therefore, the Thai government has sought to locate at least some economic activities away from the capital. In particular, it has followed the thinking of the ADB and similar organizations in reclassifying what had previously been considered to be peripheral border regions with less-developed neighbors as potential centers for enhanced economic growth. Suitable infrastructure, it is thought, could make possible the aggregation of complementary resources so as to encourage production, which would not otherwise be profitable. There are also political considerations at play, since the majority of supporters for the Pheu Thai government are drawn from the poorer people from regions such as Nakhon Phanom, while Bangkok voters continue to prefer the right-wing pro-establishment Democrat Party. Respondents in this research generally welcomed the opportunity for economic growth that recent changes offered but were concerned about their ability to cope with change. Clearly, therefore, there is a role for government in this context to find ways to help people empower themselves such that they can respond proactively to change. Given the lengthy legacy of top-down, paternalist management in Thai society, tackling the issue will be, at best, a lengthy and troublesome project.

\section{Conclusion}

Outlying regions of Thailand, in common with the outlying regions of other Mekong Region countries, have become accustomed to taking a back seat to the authorities in the centre of the state. As a result, when change comes, the people are often unprepared to deal with that change and have tended to appeal to the state for assistance, thereby intensifying the bonds of dependency. This research contributes to better understanding of this issue without necessarily supplying any answers as to how to resolve it, which would be the task of 
further research currently under way. It is possible that intensifying existing and potential local networks would assist in this case but it remains to be seen how much difference this will actually make. Both the opening of the Bridge and the promised arrival of the AEC have produced limited changes in the business community of Nakhon Phanom to date. In part, this is not surprising given the situation outlined above. However, there nevertheless remains the situation that any benefits that might be derived from these changes will be captured by other interests and so the local people and organizations may become locked into low income-generating activities. There are, after all, numerous examples depicting how aggregate increases in income and opportunity hide the negative impacts suffered by individuals. It is far from certain that local government agencies have sufficient technical capacity to identify where these incidents occur and to address them effectively. Local facilities in Nakhon Phanom currently produce only a limited number of skilled workers and many of these moves away from the province in order to find suitable work. In addition, the facilities in the province represent only a small amount of demand for skilled professionals. It is possible, therefore, for Nakhon Phanom to be a region in which the development of unevenness is intensified and inequalities of opportunity and income unaddressed. This is what has been determined from the research findings in this case. Access to resources and to markets is being provided on a partial and uneven basis and, hence, not everyone will be able to take advantage of them on an equal basis. This includes access to jobs, to stable livelihoods and to changes in patterns of land ownership. As the region has become increasingly linked to international markets, those who benefit most are those who have access to more capital, whether it is in the form of personal transportation, social capital in the form of network membership or the ability to invest in the larger scale commercial activities that can take advantage of economies of scale more likely to be successful.

\section{References}

Asian Development Bank (ADB). (2010). Strategy and Action Plan for the Great Mekong Sub region East-West Economic Corridor. Manila: ADB.

Department of Agricultural Economics (DOEA). (2011). Annual Report of the Production of Rubber Trees in Nakhon Phanom Province, Year 2009/2010. Available at: http://www.nakhonphanom.doae.go.th/data/industial52.html (in Thai).

Gomez, J. E. Jr., Southiseng, N., Walsh, J. \& Sapuay, S. (2011). Reaching across the Mekong: Socioeconomic and Gender Effects of Lao-Thai Crossborder Linkages. Journal of Current Southeast Asian Affairs, 30(3), 123.

Harvey, D. (2011). The Enigma of Capital and the Crises of Capitalism, London: Profile Books.

Jacobs, J. W. (1995). Mekong Committee History and Lessons for River Basin Development. The Geographic Journal, 161(2), 135-48.

Kim, K. \& Wu, C. T. (1998). Regional Planning's Last Hurrah: the Political Economy of the Tumen River Regional Development Plan. Geo Journal, 44(3), 239-247.

Marshall, A. (1920). Principles of Economics, London: Macmillan.

Nahapiet, J. \& Ghoshal, S. (1998). Social Capital, Intellectual Capital and the Organizational Advantage. The Academy of Management Review, 93(2), 242-66.

Ockey, J. (2005). Making Democracy: Leadership, Class, Gender and Political Participation in Thailand, Chiang Mai: Silkworm Books.

Otsuko, K. \& Sonobe, T. (2009). Geography of Cluster-Based Industrial Development, in Y. Huang and A.M. Bocchi, eds., Reshaping Economic Geography in East Asia, Washington, DC: World Bank, 19-32.

Ricardo, D. (2004). On the Principles of Political Economy, Mineola, NY: Dover Publications Inc.

Rigg, J. \& Wittayapak, C. (2009). Spatial Integration and Human Transformations in the Greater Mekong Sub region, in Y. Huang and A.M. Bocchi, eds., Reshaping Economic Geography in East Asia, Washington DC: World Bank, 79-99.

Rigg, J., Veeravongs, S. Veeravongs, L. \& Rohitarachoon, P. (2008). Reconfiguring Rural Spaces and Remaking Rural Lives in Central Thailand. Journal of Southeast Asian Studies, 39(3), 355-381.

Sciortino, R. \& Punpuing, S. (2009). International Migration in Thailand 2009, Bangkok: International Organization for Migration.

Smith, N. (2010). Uneven Development: Nature, Capital and the Production of Space, third edition with a new afterword, London and New York: Verso. 
Sonobe, T. \& Otsuka, K. (2006). Cluster-based Industrial Development: An East Asian Model Basingstoke: Palgrave Macmillan.

Southiseng, N. \& Walsh, J. (2012). Cross-border Trading Experiences before and after the Construction of the Second Lao-Thai Friendship Bridge, in K. Kusakabe, ed., Gender, Roads, and Mobility in Asia, Rugby: Practical Action Publishing, 109-20.

Swe, T. \& Chambers, P. (2011). Cashing In across the Golden Triangle: Thailand's Northern Border Trade with China, Laos and Myanmar, Chiang Mai: Mekong Press.

Theparat, C. (2012). New Thailand-Laos Bridge Needs More Support, Bangkok Post (February 22nd), 4.

Trankell, I. B. (1999). On the Road in Laos: An Anthropological Study of Road Construction and Rural Communities, Bangkok: White Lotus.

Vandamme, F. (2000). Labor Mobility within the European Union: Findings, States and Prospects. International Labor Review, 139(4), 437-55.

Walsh, J. (2011). Cranes among Chickens: Chinese Investment in Mainland Southeast Asia, paper presented at the Workshop on Chinese Investments in Southeast Asia, Hong Kong: Southeast Asia Research Centre, City University of Hong Kong.

Yip, G. S. (2000). Asian Advantage: Key Strategies for Winning in the Asia-Pacific Region, New York: Perseus Books.

Yukubousky, M. C. (2012). Preparation for the AEC: Free Flow of Services, Bangkok Post (March 23 ${ }^{\text {rd }}$ ), B3.

Zimmermann, K. F. (2005). European Labor Mobility: Challenges and Potentials. De Economist, 153(4), 42550. 